\title{
Erratum to: Community factors to promote parents' quality of child-nurturing life
}

\author{
Megumi Aoyama $\cdot$ Chang Nian Wei \\ Koichi Harada $\cdot$ Kimiyo Ueda • Miyuki Takano • \\ Atsushi Ueda
}

Published online: 13 November 2012

(c) The Japanese Society for Hygiene 2012

\section{Erratum to: Environ Health Prev Med \\ DOI 10.1007/s12199-012-0303-9}

The co-author's name and the result of the abstract were incorrectly published in the original publication. The errors are corrected as given below.

The second author's name was misspelled and corrected as in this article.

In the abstract the sentence "The analysis revealed that community factors had a positive relation to parents'
QCNL $(r=0.81, p<0.001)$ and that parental SDS score had a negative relation to parents' QCNL $(r=-0.59$, $p<0.001$ )" should read as

The analysis revealed that community factors had a positive relation to parents' QCNL $(r=0.81, p<0.001)$ and that parental SDS score had a negative relation to community factors $(r=-0.59, p<0.001)$.

The online version of the original article can be found under doi:10.1007/s12199-012-0303-9.

M. Aoyama $(\square) \cdot$ C. N. Wei · A. Ueda

Department of Preventive and Environmental Medicine,

Kumamoto University Graduate School of Medicine,

1-1-1 Honjo, Kumamoto 860-8555, Japan

e-mail: megumi_aoyama@s7.kcn-tv.ne.jp

K. Harada

Department of Biomedical Laboratory Sciences,

Faculty of Life Sciences, Kumamoto University,

Kumamoto, Japan

K. Ueda

Department of Community Health Nursing,

School of Health Sciences, Kumamoto University,

Kumamoto, Japan

M. Takano

Department of Clinical Psychology,

Kyushu Lutheran College, Kumamoto, Japan 